\title{
O futuro do livro na avaliação dos programas de pós-graduação: uma cultura do livro seria necessária?
}

\author{
The future of books as evaluated by post-graduate programs: \\ is a book culture necessary? \\ El futuro del libro en la evaluación de los programas de postgrado: \\ ¿Una cultura del libro sería necesaria?
}

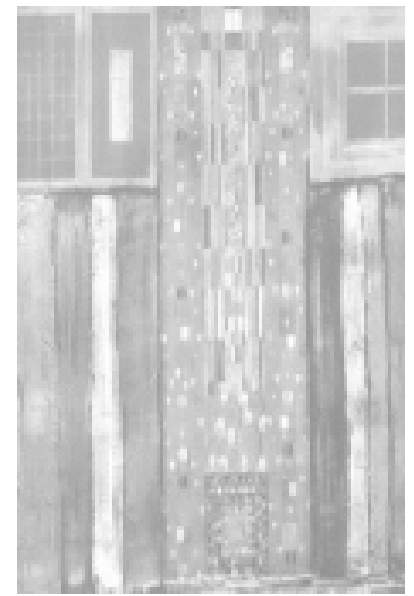

Madel T. Luz

\section{O livro: uma cultura em crise?}

Certamente a mutação tecnológica produzida nas ultimas décadas do século passado nas formas de comunicação ou, termo mais correntemente empregado, na difusão do conhecimento científico ou artístico, trouxe para o que se pode denominar, desde o século XVII, de cultura do livro, uma situação problemática, diríamos mesmo de crise .

O que queremos dizer aqui com a expressão cultura do livro? Não estamos nos referindo apenas a uma forma específica de difusão sistemática de informações e de descobertas por meio de um objeto material com certas características -papel, impressão, tinta gráfica: estamos nos referindo ao livro como depositário central, na cultura moderna, não apenas da transmissão do pensamento estruturado em forma de filosofia, ciência ou arte, ou da divulgação da informação considerada socialmente importante, mas também da circulação do imaginário, dos comportamentos e dos sentimentos humanos. Em suma: da expressão formal da cultura em todos os seus aspectos. É isto que designamos aqui como "cultura do livro". Deve ser assinalado que esta cultura dominou a história da educação desde o século XVII. Praticamente toda a pedagogia dos últimos três séculos apoiou-se no livro como instrumento básico do ensino. De fato, em última análise poder-se-ia falar em uma civilização do livro na modernidade

Sucede que o livro como instrumento de transmissão cultural apóia-se em um tipo de linguagem específica, a da língua falada e escrita pelos povos, independentemente do idioma em que é expressa. Uma exceção deve ser feita, naturalmente, às obras científicas escritas em linguagens altamente abstratas - praticamente codificadas - sobretudo as matemáticas, ou assimiladas a ela, que têm, ainda assim, o desenvolvimento do raciocínio com seus enunciados intermediados pela linguagem dita literária, mesmo concisa, no sentido de evidenciar-Ihes a lógica na sequêencia do processo demonstrativo/ explicativo.

O livro é, portanto, também, linguagem em si mesma, código e mensagem ao mesmo tempo, linguagem apoiada na língua, materializada nos idiomas, cada qual com suas normas sintáticas e gramaticais, exigências formais de expressão de conteúdo, regras de

\footnotetext{
${ }^{1}$ Professora titular, Instituto de Medicina Social, Universidade Estadual do Rio de Janeiro (IMS/UERJ). <madelluz@superig.com.br>
} 
estilo etc. Em suma, trata-se de um objeto de comunicação de grande complexidade, diferente de outras formas de impressos, como os folhetos, os panfletos, os manuais e "calendários" de todos os tipos, todos contemporâneos do livro, pois frutos da mesma matriz, a imprensa, e filhos do mesmo pai da modernidade escrita, Gutemberg.

Se acrescentarmos ao conjunto de exigências lingüísticas da produção de um livro todo o progressivo acúmulo histórico de normas de expressão referentes às diferentes disciplinas que constituem a árvore do conhecimento humano, teremos uma idéia aproximada da complexidade do objeto livro como transmissor de cultura, seja ela artística ou científica. Pois o "estilo", se ousarmos empregar livremente esta expressão a propósito da linguagem das ciências - próprio das disciplinas é bastante específico (especializado seria um termo mais adequado aos dias de hoje) em cada uma delas, não sendo admitidas pelas respectivas comunidades de autores e pesquisadores, "importações" ou "transferências" de formas de expressão ou conteúdos - isto é, de linguagem- de uma para outra sem grandes restrições de natureza metodológica e epistemológica. O autor, sobretudo o autor científico, é apenas aquele agente social que conhece e sabe lidar bem com todas essas exigências, raramente transgredindo-as, e quando as transgride é geralmente no sentido de propiciar o avanço do conhecimento em sua disciplina. $O$ autor não é o ator principal no processo que gerou a obra, mas sim a obra em si mesma, isto é, o livro. Em linguagem teatral seria dito: a personagem é quem importa e não o ator. A personagem é o livro, e o ator é o autor, encarregado de "dar à luz" seu personagem livro. Este sim, poderá, por suas características de força inovadora em termos de linguagem e conteúdo, provocar mudanças importantes no conhecimento, na forma de expressar-se -linguagem - ou na conduta humana.

\section{A (des) valorização do livro na cultura contemporânea: fim de um ciclo civilizatório?}

Um momento de confusão cultural tende a se instalar quando esse objeto secular (alguns estudiosos afirmam mesmo milenar, se considerados os pergaminhos e outras formas de "escritura" do livro não impressa, como caracteres oriundos de civilizações antigas ou orientais) perde seu espaço privilegiado de transmissor de conhecimento e arte, como sucede atualmente. Não nos referimos simplesmente ao objeto material, pois o livro pode tomar atualmente variadas formas, dentre as quais a virtual, tão em voga no presente, mas sobretudo ao objeto simbólico, cujos conteúdos são o centro de transmissão da cultura.

Outras formas de expressão impressas, abreviadas ou codificadas, derivadas do livro (não nos deteremos aqui na análise da explosão contemporânea das linguagens centradas na imagem, ou no mix imagem/ palavra codificada, dominantes no mundo da comunicação virtual que, é certo, em breve atingirão a difusão científica, e seu impacto sobre o livro), sobretudo o artigo, ou mais simplesmente o paper impresso, designando a publicação de um momento particular da investigação científica, ou sua conclusão, tomaram, desde o fim do século XIX, cada vez mais o espaço de difusor da ciência, e depois da arte, tendo gerado hierarquias de valor na difusão do conhecimento. Estas hierarquias valorativas das formas de expressão e difusão da pesquisa, conduzidas pela autoridade epistemológica das ciências ditas exatas, ou "duras", tornaram-se progressivamente discriminatórias do livro como expressão da produção de conhecimento. Tais hierarquias, oriundas do próprio mundo acadêmico, isto é, basicamente de lideranças das grandes universidades e dos institutos de pesquisa, tenderam a se institucionalizar nos últimos vinte anos nas agências públicas de financiamento à pesquisa, centrais ou estaduais, nas quais predominam também líderes pesquisadores das ciências duras, criando-se um status quo tácito de desvalorização acadêmica dessa forma de transmissão e difusão do conhecimento, científico e artístico, na maioria dos ramos da árvore dos saberes. Mesmo nas ciências humanas, até há quinze anos centradas no livro para a difusão de suas atividades, há uma concepção crescente que o livro é um instrumento "menor" de divulgação de resultados de pesquisa, ou até mesmo de produção inovadora de conhecimento, tendo aumentado claramente na última década a proporção de artigos no campo, afirmando assim a marca da hegemonia do "estilo" de 
comunicação das ciências exatas sobre a difusão do conhecimento científico.Do nosso ponto de vista, a perda progressiva do "estilo" de comunicação das ciências humanas na difusão do conhecimento repercute negativamente na própria produção do conhecimento.

A tal ponto que está presente na comunidade acadêmica uma concepção tácita que o livro, como produção científica singular, constando de um conjunto de conteúdos disciplinares atribuíveis a um autor, ou mesmo a vários, seria inavaliável objetivamente, sendo por este motivo praticamente inafiançável como veículo difusor de conhecimento, uma vez que o julgamento sobre o caráter científico dos conteúdos desse objeto único não se embasaria em critérios objetivos de avaliação. Este já não seria o caso do paper, a ser publicado em órgãos de difusão qualificados, dispondo de um conjunto de parâmetros de avaliação, dentre os quais sobressai-se o peer review, isto é, o julgamento avaliativo do pesquisador e seu produto pelos pares acadêmicos trabalhando no mesmo campo e pesquisando eixos temáticos semelhantes ou próximos. Além deste critério de atestação de qualidade há outro, indireto, de estabelecimento da qualidade do produto artigo, que é o número de citações do mesmo em trabalhos publicados sobre o tema, isto é, seu "índice de impacto" no campo.

Costuma-se entender, neste contexto, objetivo como quantificável, isto é, passível de evidenciar-se, e reproduzir-se, quanto aos conteúdos/afirmações, em termos de tabelas, curvas ou gráficos, mas quantificável principalmente no que concerne ao seu número provável de leitores e sobretudo, o que não é a mesma coisa, em termos do índice de citações do trabalho (pense-se que um só leitor pode citar várias vezes o mesmo trabalho), o que atestaria, por seu "impacto" na área, sua qualificação face à comunidade científica.

Chegamos neste ponto a um paradoxo: o critério quantitativo do impacto não nos garante que o produto artigo seja efetivamente inovador ou original, isto é, nada nos diz sobre sua efetiva qualidade. Se na origem do processo da publicação, na avaliação dos pareceristas do órgão difusor, houver parti pris, contra ou a favor do produto, jamais se saberá se o produto é ou não cientificamente relevante. O valor do artigo científico em termos de conteúdo é assim, de certa forma, inefável. O que já não sucede com um objeto de arte -ou até mesmo com um livro - cuja qualidade é imediatamente apreensível. No caso da avaliação de artigos, tem-se que supor que os pareceristas ajam isentos de valores e escolhas prévias metodológicas ou teóricas, isto é, de pré conceitos. Supõem-se que sejam neutros.

Para as ciências sociais não há neutralidade axiológica na construção do conhecimento.

Quando se considera o pequeno número de veículos de difusão existentes perante a

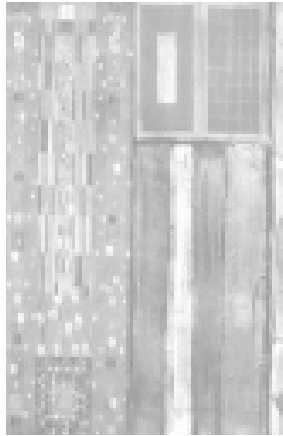
oferta de trabalhos, visto o crescimento das atividades de pesquisa nas últimas décadas, a inclusão de um artigo em veículo constante das bases "Qualis" já mencionadas, a luta pelo acesso a esses veículos transforma tais bases em uma pirâmide social hierárquica da difusão do conhecimento, e neste caso não apenas dos trabalhos -ou seus autores- mas principalmente dos próprios veículos difusores. Essa hierarquia gera freqüentemente duas distorções acadêmicas principais:

1 um artigo/autor é avaliado como mais ou menos importante, não em função do eventual caráter inovador ou criativo do trabalho, mas em função do lugar do veículo de difusão na hierarquia dos veículos em relação à(s) base(s) de qualificação ("qualis"), existente(s) no campo em que se insere o trabalho. Ora, tais bases são socialmente geradas, isto é, organizadas com escolhas de critérios classificatórios específicos perante o campo em que se inserem, pautadas em termos dessas escolhas de critérios por agentes sociais específicos, individuais ou grupais, que tem interesses também específicos em suas respectivas áreas, em termos de status, prestígio e poder no campo científico em que operam;

2 ratificadas academicamente as hierarquias de veículos, os autores desencadearão um processo competitivo desenfreado para publicarem seus trabalhos nesses mesmos veículos, buscando neles estabelecer-se permanentemente como autores de referência. 
Como conseqüência, uma tendência à circularidade nas citações de autores tende a se formar, originando um círculo vicioso já conhecido academicamente (os mesmos autores citando sempre os mesmos trabalhos/autores).

Resumindo: publicar um artigo numa revista de nível Qualis A não remete, em si, à criação científica ou à inovação tecnológica mas geralmente à reprodução do conjunto disciplinar de conhecimentos estabelecidos, que Kuhn designava como "ciência normal".

Por outro lado, trabalhos originais e inovadores são continuamente publicados por jovens pesquisadores em veículos de nível menos qualificado, ou mesmo, às vezes, não incluídos em bases "Qualis", não sendo por isto considerados como produção nem por seus pares nem pelas agências de fomento à pesquisa. De nosso ponto de vista, isto tende a ratificar as bases de qualificação de veículos difusores como fatos culturais, isto é, como produto da construção de agentes que incluem nessas construções interesses específicos em termos de estatuto e prestigio social em seus campos, e ações sociais em função desses interesses.

\section{O futuro do livro nos processos de avaliação dos programas de pós-graduação pela CAPES: uma cultura do livro seria necessária no Brasil?}

No que concerne ao livro como um objeto singular perceptível, que "fala por si mesmo" menção aqui á idéia de "personagem", feita páginas atrás - para ser efetivamente avaliado,

isto é, sobre se de fato contribui ou não para o avanço do conhecimento no campo em que se insere, em termos de originalidade, inovação ou mudança, seja em seus conteúdos substantivos em ou sua linguagem, necessita da construção de parâmetros objetivos específicos de avaliação. Tais parâmetros são, por princípio, irredutíveis àqueles quantitativos ligados às bases de qualificação de veículos aqui analisadas, pois os livros devem ser avaliados basicamente quanto à qualidade de seus conteúdos. As bases "qualis" são geralmente privadas e custosas (apenas começam a surgir nesta década bases públicas de classificação/inclusão de veículos, construídas a partir de critérios estritamente acadêmicos e biblioteconômicos, com a participação de pesquisadores líderes de todas as áreas de conhecimento) e visam a enquadrar os veículos difusores dos papers de pesquisa das ciências quantificáveis, de cuja qualidade inovadora em termos de produção de conhecimento não se pode, como vimos acima, ter noção exata.Não se aplicam aos livros.

Os parâmetros de avaliação dos livros estão, por sua vez, ainda em construção. Diríamos mesmo mais em debate, neste momento. Devemos, como pesquisadores, sobretudo os das ciências humanas e sociais, não apenas aguardar a construção desses parâmetros, mas antecipá-la, dela participando ativamente, buscando nos comprometer com os resultados de sua construção. Desvalorizar, neste momento, ou aceitar a desvalorização do livro como instrumento mor de difusão da cultura científica e artística seria fazer prova, no Brasil, de uma concepção atrasada da divulgação do conhecimento na cultura mundial contemporânea, num momento em que na Europa, ou na França pelo menos, o livro apresenta grande revitalização como difusor da ciência e da arte. Na França, de onde escrevemos estas páginas, a cultura do livro, ameaçada pela "cultura da imagem", é tema de debates patrocinados tanto pelo poder público como por instituições sociais e fundações privadas, como empresas e editoras. Tanto nas escolas, como nas universidades, e nos museus - que aqui são centros vivos de transmissão cultural - assim como na mídia em geral, tanto a da imagem, como a impressa e a falada, o livro, mais que um personagem, é um verdadeiro ator social .É centro de tema de debates diários nos canais abertos de televisão, nas rádios, nas palestras acadêmicas, nas exposições, até mesmo nos cafés. Evidentemente os autores aí estão sempre presentes, bem como seus críticos, seus interlocutores acadêmicos, representantes da sociedade civil, dos partidos, do Estado. Enfim, pode-se dizer que há uma sólida cultura do livro, apesar do embate real com a civilização da imagem que, mais do que se anuncia, se instala já pelo mundo inteiro. Mas não provoca o dano que tem provocado em países como o Brasil, onde o livro como 
transmissor de conhecimentos restringiu-se a uma pequena parcela da população.

Em outras palavras, não há aqui nenhuma dúvida sobre o caráter central do livro na difusão do conhecimento científico e artístico. Ele continua sendo o item nobre da produção artística e científica, independentemente dos papers científicos publicados em revistas importantes.

O mesmo já não se pode dizer do Brasil, apesar dos esforços recentes de reconhecer o livro (ou o capítulo de livro coletânea) como efetiva produção científica, ligado à atividade da pesquisa junto aos órgãos centrais de fomento à pesquisa, sobretudo a CAPES.

A mentalidade ainda predominante no mundo acadêmico é de desqualificação do livro como produção de primeira grandeza do conhecimento. Em nossa experiência de anos como membro de CA de área (Saúde Coletiva) tanto da CAPES como do CNPq, e de comissões de análise e de criação de parâmetros de avaliação do livro da ABRASCO (Associação Brasileira de Pós-Graduação em Saúde Coletiva) desde o fim da década de 1990, fomos chegando ao consenso,em nossa área, que há pelo menos cinco parâmetros de avaliação a serem considerados no caso dos livros (incluídas as coletâneas):

1 A fonte de edição dos mesmos, isto é, a editora, tem de ter a confiança da comunidade científica/artística no campo onde se insere (tradição de qualidade). Não necessita ser, para isto, estatal, ou ligada a universidades ou institutos de pesquisa. Sua tradição de qualidade deve ser atestada não apenas: a) pela qualidade dos livros que editou em seu percurso; b) a regularidade com que o fez, mas também; c) pela capacidade que tem de editar obras originais e inovadoras no campo, sejam seus autores líderes já conhecidos ou jovens talentos. Editoras universitárias, por sua ligação com os pesquisadores, têm oportunidade de responder melhor a este último item, mas algumas do mercado editorial, sobretudo nas ciências humanas: filosofia, psicanálise, sociologia, comunicação etc, também o fazem.

Não é necessário, é claro, que a editora tenha produzido best sellers, num país em que um livro produto de uma pesquisa específica não pode ultrapassar, geralmente, dois mil exemplares. Pois a editora de livros difusora do conhecimento não está pautada na lógica do grande número de impressões ou exemplares.

2 A existência de um corpo ou conselho editorial respeitado no campo, formado por pesquisadores líderes da(s) áreas(s) do mesmo, é um requisito importante para qualificar a editora. O conselho editorial poderá eventualmente pedir pareceres de autores que trabalham na área do livro em questão, buscando analisar a qualidade do produto/livro, quanto à linguagem, ou conteúdo, geralmente ambos, visando sua avaliação.

$3 \mathrm{~A}$ existência de séries ou coleções relativas aos temas das áreas em que se inserem as obras, coordenadas por um líder ou equipe de autores da área.

4 A qualidade da edição e revisão do objeto livro.

5 A persistência da editora (diferente de regularidade de publicação) num determinado período de tempo. Uma editora não pode ter uma existência fugaz, como uma loja que vende produtos importados, ou coisa similar.

No que concerne ao produto livro: deve ser assegurado, pelos parâmetros aqui propostos de avaliação, se este contribui, efetivamente, por seus conteúdos substantivos, por sua linguagem ou por ambos, para o avanço do conhecimento científico ou artístico de sua área. O que gostaríamos de deixar claro, ao finalizar essas observações sobre o futuro do livro nas avaliações dos programas CAPES, é que temos a possibilidade de efetivamente avaliar o produto livro em sua qualidade e ter noção objetiva de sua contribuição, existente ou não, para a área/campo de inserção. Este processo relativamente de construção está em debate e em marcha, como assinalamos atrás. O que realmente preocupa é que não haverá nenhum futuro para o livro, em nenhum nível de difusão do conhecimento, se não se construir, entre nós, uma cultura do livro. E, neste campo, tudo está ainda por ser construído. 


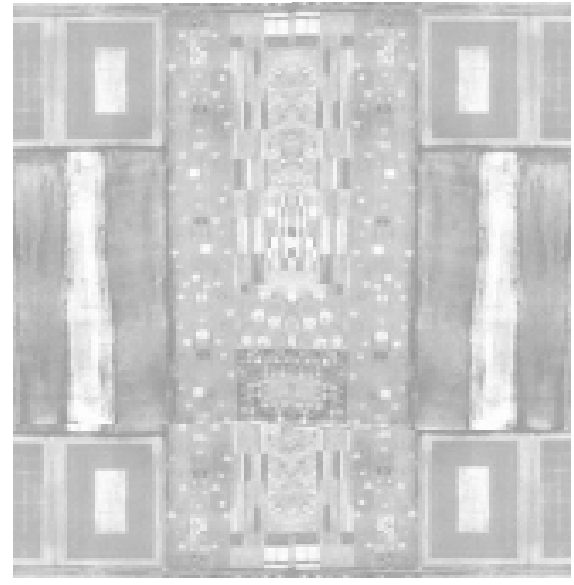

The future of books in contemporary culture is discussed, reiterating their contribution to the progress of knowledge in different fields and stressing the need to construct parameters for evaluating books that can ensure their contribution to the defense of science produced in Brazil. KEY WORDS: book culture. science. scientific progress. evaluation.

Discute-se o futuro do livro na cultura contemporânea, reafirmando sua contribuição para o avanço do conhecimento nas diferentes áreas e ressaltando a necessidade da construção de parâmetros de avaliação de livros que assegurem sua contribuição para a defesa da ciência produzida no país. PALAVRAS-CHAVE: cultura do livro. ciência. avanço científico. avaliação.

Se discute el futuro del libro en la cultura contemporánea, reafirmando su contribución para el avance del conocimiento en las diferentes áreas y resaltando la necesidad de la construcción de parámetros de evaluación de libros que garanticen su contribución para la defensa de la ciencia desarrollada en el país.

PALABRAS CLAVE: cultura del libro. ciencia. avance científico. evaluación. 